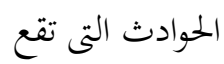

\title{
الحوادث التى تقع يوم القيامة وتذكر في القرآن الكريم
}

\section{Malia Fransisca}

Institut Agama Islam Sunan Giri Bojonegoro

Email: malia_fransisca@yahoo.com

\begin{abstract}
Doomsday is divided into two: Sughro Doomsday and Kubro. Sughro doomsday like death, accidents, illness, etc. Kubro doomsday happen when the earth is shaken with fierce, all of the material the earth out, destroyed all of the universe. After that there is no life in the world. because life is actually going to happen in the hereafter. At the end of days coming, people running around like flying white ant. They are confused don't know where they are going. The sky split. The ocean overflows. The mountains were destroyed all the way to dust. They are afraid of this terrible situation. They left and forget all valuable things, because at the time that can only help them is charity of their deeds, not possessions or property the other in the form of earthly.
\end{abstract}

Keyword: Doomsday, Shaken, Destroyed, Hereafter.

مقدمة

كانت القيامة نوعان: الصغرى والكبرى. فأما قيامة الصغرى مثل الموت والحوادث والمرض وما أشبه ذلك.

وأما قيامة الكبرى عندما زلزت الأرض وينزل المطر قيل أربعين يوما. جميع ما في الأرض يخزج منها. بعد ذلك،

ما في الحياة في الدنيا. لأنّ الآخرة هو حقيقة الحياة. ويعيش الناس فيها دائما. يهلك الأرض هلكا شديدا.

كانت الجبال زلزلت وهلكت. يجرى الناس كالفراش المبثوث. هم يتحيرون إلى أي المكان يتجهون. ما الشخص

الذي يستعينه لأنّ الناس حينئ يفكرون أنفسهم بل لا يفكرون أبآههم وأبناءهم وأمهاقم وأخواقم وأصدقائهم

وأساتيذهم. 
قال محمد علي الصابوني في سورة الواقعة أية ا: "إذا وقعت الواقعة" أي إذا قامت القيامة التى لابد من وقوعها، وحدثت الداهية الطآمة التى ينخلع لها قلب الإنسان، كان من الأهوال ما لا يصفه الخيال. '

يُذكرَ يومُ القيامة في القرآن الكريم بتنوع الاصطلاح. ومنهم الساعة (الأنعام: •ـع) ويوم البعث (الروم: به ويوم الدين (الحجر: 0ب) ويوم الحسرة (مريم: 91 ) ودار الخلد (فصلت: عه) ويوم الخلود (ق: عץ)

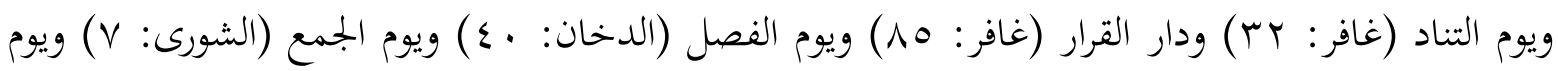

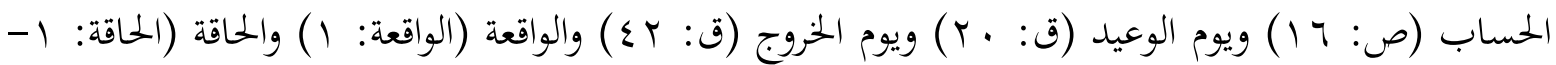

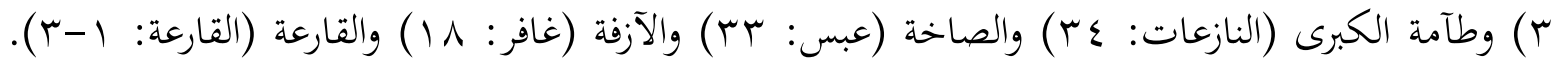
ينقسم يوم القيامة قسمين: القيامة الصغرى والكبرى. فأما القيامة الصغرى مثل مات الرجل وحادث في الشارع ويشعر بالمرض وما يشبه ذلك. وأما القيامة الكبرى هي عندما زلزلت الأرض ويهلك ما في السموات والأراضي جميعا في العالم. وبعد ذلك ما وجدنا في الأرض ولو شيئا. ما الموجود الحياة في الأرض لأنّ حقيقة الحياة هي في

إنّا لا نعرف كيف تقع القيامة حقيقة لأن لم تحدث هذا اليوم. لكن نجب علينا أن نؤمن بوجودها وبوقوعها لأن القرآن الكريم وضحها في بعض السورة. أما الحوادث يوم القيامة فكما يلي:

\section{1. عندما ينشق وينفطر ويكشط السماء}

إن نعرف بأن المطر ينزل من السماء. إما ينزل بتقليل الماء وإما بكثرة حتى يقع الفيضان. وقيل المطر ينزل البركة لولا يقع الحوادث مثل الفيضان والاغيار. كيف حينما ينزل المطر فيقع الفيضان والاغيار؟ هذه مصيبة. حقيقة، يقع المطر ليس لانشقاق السماء ولا لانفطارها. يقع المطر لانشقاق نقط السحاب بسبب بجرى الهواء. ذلك الأمثال لتوقيع المطر.

$$
\text { ' محمد علي الصابوني، "صغوة التغاسيز: المجلد الثاني"، (بيروت: دار القرآن الكريع، ال1911)، ص. ه.بr }
$$




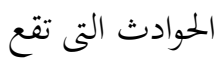

انشقاق نقط السحاب يسبب الفيضان والاهيار، فكيف حينما انشقاق السماء؟ هذه هي تقع القيامة. نحن لانستطيع أن نخيل كيف انشقاق السماء وماذا ينزل بعد انشقاقها. هذه هي يوم الأخير في الدنيا. فطبعا هدم الدنيا وما فيها. كما قال الله تعالى في سورة الانشقاق أية ا: "إذذا السَّمَاءُ انْشَقَّتُ" وسورة الانفطار أية

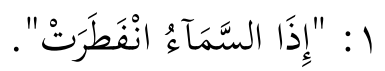

قال الله تعالى في سورة التكوير أية 11: "وَإِذَا السَّمَاءُ كُشِطَتْ". عندما نفكر كيف يكشط الله السماء فلا قدر عقولنا أن نخيلها. ولكن ذُكرِر القرآنُ وطبعا نوجد الشرح منه. عندما يقول الله كن فيكون ويريد الله أن يكشط السماء، ماذا نفعل؟؟؟ له ما في السموات والأرض. عندما يكشط السماء فيهلك الأرض لأنّ جميع المواد في السماء تخزج منها وتسقط على الأرض وما حولها. عندما يقع ذلك الحدث فيقع يوم القيامة.

قال الله تعالى في سورة الانفطار أية ؟ : "وإذا الكواكب انتثرت". سمعنا كثيرا أن الشهاب تقع إلى الأرض قبل مليون سنة، وماذا حدث؟ فصار هدم الطين هناك ويسبب هاوية كبرى. هو شهاب واحد. وكيف حينما تقع الكواكب في الأرض وتنتشر فيها؟ حينئ، سوى الهاوية الكبرى تزلزلت الأرض تزلزلا شديدا. فتقع يوم القيامة. غير موجود المكان لحياة الناس. هدمت الأرض وحرقت بتوقيع الكواكب. في ذلك اليوم لا يقدر الناس أن يفعلوا الأشياء إلا بسطع أعيوغم. هم يتحيرون إلى أي المكان سيذهبون. هلكت البنيان والعمارات والأماكين العالية والشوارع والأبحر والجبال والفنادق وجميع ما في الأرض.

ذكر الله عن القيامة في سورة الانفطار أية ب: "وَإِذًا الْبِحَارُ فُعِّرَتْ". الآن... خصوصا في بلادنا، تقع الحوادث كثيرا مثل زلزلة الأرض في البحر التي تسمى بالسونامي. نعود بالله من شرور أنفسنا وغيرهم. هذه الحوادث تقع في سولاويسي الذي يسبب كثرة المصاب مرتين في هذه السنة. ووقع سونامي أيضا في أجيه سومطرا الشمالية في السنة ع . . ب م. هما مثالان الصغيران اللذان في إندونيسيا فقط. نحن لم نذكر الذي يقع خارح البلد. مثلا....... يقع سونامي معا أي تطابق وقعه في الأرض معا، فماذا يحدث؟ الإجابة هي فتقع القيامة. في لمحة البصر، هلك حول البحر دقيقتين فقط. خرج الماء من البحر سرعة وبتشديد الخطفة. وكان موج البحر كبيرا جدا ويسبب جميع ما هناك جلبت بالماء. 
قال أحمد مصطفى المراغى في تفسيره بأن البحار تغيرت النار بسبب الأرض يحتوى النار. وتظهر النار بزلزلة الأرض. حينئذ، تغير الماء الدخان ولا بقي إلا النار.'

قال الله تعالى في سورة الانفطار أية ع : "وإذا القبور بعثرت". أي بعثر من يموتون ويتجهون إلى المحشر ليحاسبوا أعمالهم في الدنيا. حينئذ بعثر الميت عارا أي بدون اللباس. حينئذ يقول أيديهم وأرجلهم وأعينهم

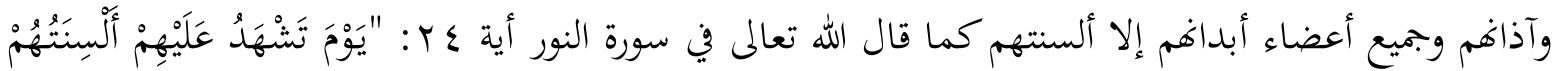

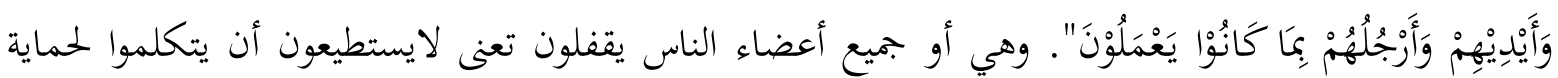
أنفسهم. كما قال الصابوني في سورة يس أية بr ب "اليوم نختح على أفواههم" أي في هذا اليوم - يوم القيامة نختم على أفواه الكفار ختما يمنعها عن الكلام. "وتكلمنا أيديهم وتشهد أرجلهم بما كانوا يكسبون" أي ينطق عليهم جوارحهم أيديهم وأرجلهم بأعمالهم القبيحة. بَ أفكر ليس من الكافرين وحدهم الذين يختمون أفواههم ولكن جميع الناس كذلك أيضا.

وحيئزذ مسؤل عما يعملون في الدنيا لأن الله تعالى يقول في سورة الزلزلة أية V-N: "فَكَمَنْ يَعْمَلْ مِثْعَالَ

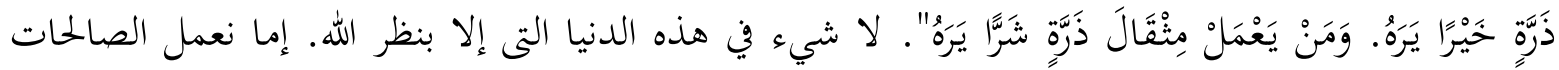
وإما السيئات. الذين لم يؤمنوا بالله فيعملوا السيئات بدون الخوف لإثّم يظنون أن الله لم يعرفوهم ولم ينظروهم. ومختلف بالذين يؤمنون بالله، هم يعلمون أن الله ينظروهم فلذلك يخشون عندما يعملون السيئات.

قال الصابوني في سورة يس أية 1 1: "ونفخ في الصور فإذا هم من الأجداث إلى ربهم ينسلون" أي نفخ في

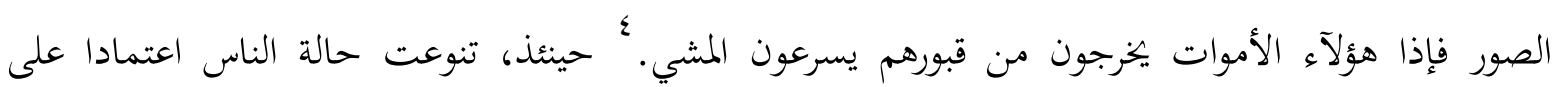
أعمالهم في الدنيا. كان الناس يشبهون الحيوانات مثل القرد والكلب والحية والدجاجة وما إلى ذلك. يمكنون في الدنيا يحبون الناس أن يغدروا بين الشخصين. ويحبون أن يتكلموا ويتجسسوا بينهم. كان الناس يحبون أن يعطوا ويتصدقوا أموالهم فلذلك عندما يخرجون من قبورهم يظهرون بالتبسم في وجوههم والناظرة.

${ }^{2}$ Ahmad Mushthafa al-Maraghi, “Terjemah Tafsir al-Maraghi”, (Tanpa Kota: 1365 H, Toha Putra), hlm. 92.

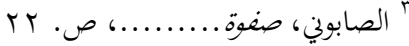

$$
\begin{aligned}
& \text { ؛ المرجع السابق، ص. 11 | }
\end{aligned}
$$




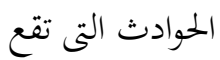

جعل الله الجبال كالعماد للأرض. عندما لا يكون الجبال، إلى أين تقبض الأرض؟ أخر الزمان، انفجرت الجبال كثيرا. لو كان هذا الحدث كثيرا يقع في الأرض، هدمت الأرض. كما قال الله تعالى في سورة الانشقاق

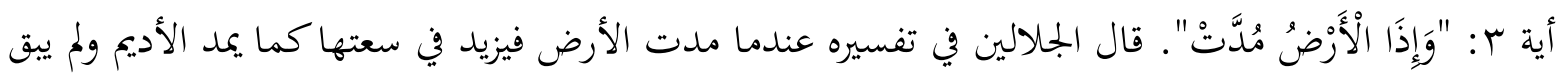
عليها بناء ولا جبل.

تحدث المراغى عن هذا الحدث في تفسيره: "عندما زلزلت الأرض وانفجرت الجبال، فتهلك الجبال تساوى

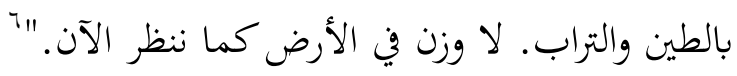

قال الله تعالى في سورة القارعة أية ـ : "يوم يكون الناس كالفراش المبثوث". يقع يوم القيامة عند ما جمع ما في الأرض يتحرك مجرى الهواء والماء. ضرب الله مثلا بأن الناس مثل الفراش المبثوث مجرى الهواء. هذا هو الدليل بأن الناس أصغر جدا حتى يضربه الله بالفراش الذي لايعرف الاتحاهات. هو يجري مجرى الهواء. قال الله تعالى في سورة القارعة أية ه: "وتكون الجبال كالعهن المنفوش". كان الجبل واحد الذي يتحرك قليلا يسبب بزلزة الأرض. فكيف إذا كان الجبال التى ضرب الله بالعهن يعنى بجرى الشيء الحفيف فينفخ لحظة فصار كالقطن المنفوش جرى الهواء. فهذا هي يسمى بأخير الزمان أي يقع يوم القيامة. قال أبي بكر جابر الجزائري سميت القارعة لأخا تقرع القلوب بأهواها. حتى يمثل بالفراش المبثوث أي كغوغاء الجراد المنتشر يموج بعضهم في بعض. ويمثل أيضا كالعهن المنفوش أي كالصوف المندوف هذه حالها أولاً ثو تكون كثيبا مهيلا ثخ تكون هباء منبثا.

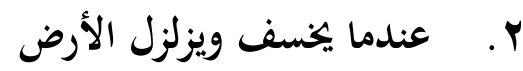

• العلامة جلال الدين محمد بن أممد الحلى والعلامة جلال الدين عبد الرمن بن أبي بكر السيوطي، "تفسير الجلالين"، (بيروت: دار الكتب العلمية،

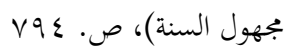

${ }^{6}$ Ahmad Mushthafa al-Maraghi, Terjemah.........., hlm. 149.

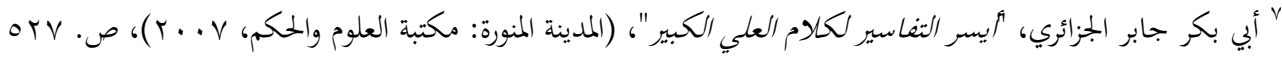


فالحادث الذي الآتي هو خسفت الأرض. يعنى يقلب الأرض بالتجاهات وهو على ما شاء الله إلى أي

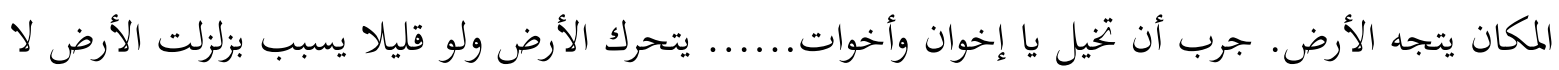
سيما عند ما يقلب الله الأرض. فيهلك هلكا شديدا وينكسر أجزائها برقة.

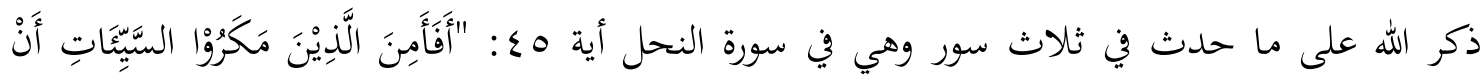

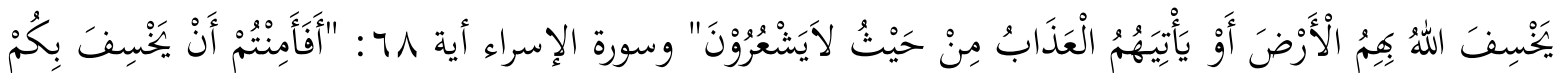

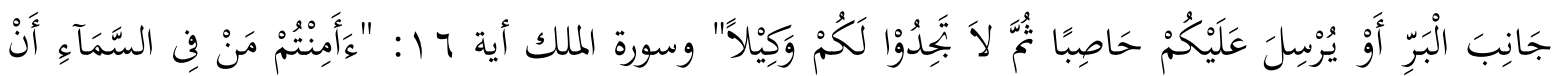

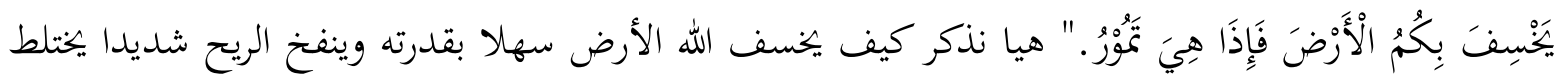
بالأحجر الصغيرة. حيئذ لا معاونة علينا لأفم يتحيرون بأنفسهم.

قال أحمد مصطفى المراغى في تفسيره بأن معنى كلمة "زلزة" هي تحرك الشيء جبارا مع الزلزلة. كما قال

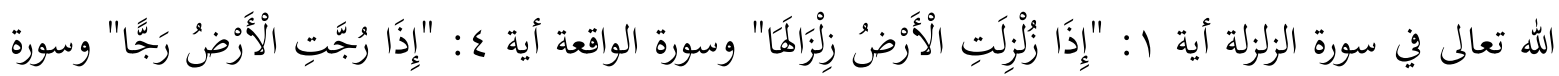

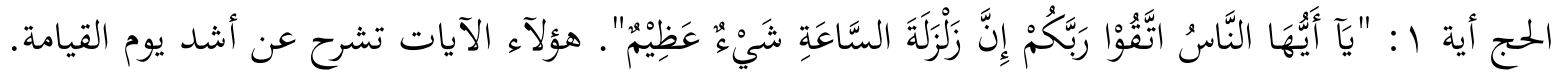
تُقصَد بأن الكافرين يريدون أن يفكروا كيف يقع يوم القيامة فيدركون الإسلام حقيقة حتى يقال إليهم: "لو كان

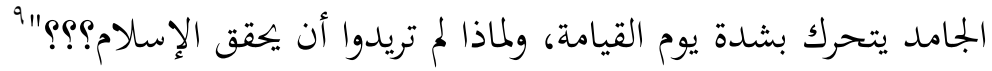

قال الله تعالى في سورة الزلزة أية r: "وأخرجت الأرض أثقالها". تعنى ما في الأرض خرج جميعا لأنّ تشعر الأرض مثقالا بكثرة المواد الأرضية. مثل نحاس ووحل وحصى وأحجار ومياه ومعادن وما إلى ذلك. هل تذكرون حدث وحل "لافيندو" بسيدوارجو في وب مايو ج .. r الماضي؟ حيئذ خرجت الأرض الوحل بعدد كبير يسبب إخلاء الناس هناك ويطلبون المسكن آخر.

قال الإمام أبي محمد الحسين بن مسعود عندما زلزلت الأرض حركت الأرض حركة شديدة لقيام الساعة.

$$
\text { وأخرجت الأرض أثقاها أي موما وكنوزها فتلقيها على ظهرها. 'ل }
$$

${ }^{8}$ Ahmad Mushthafa al-Maraghi, Ibid, hlm. 361.

${ }^{9}$ Ibid, hlm. 363.

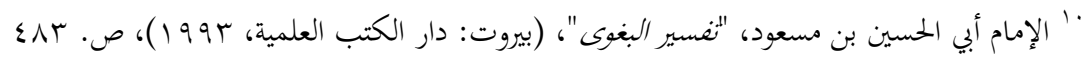


الحوادث التى تقع

قيل في تفسير ابن كثير بأن الأرض تخرج الأموات الذين في المقبر حتى تخلو الأرض منهم. '"

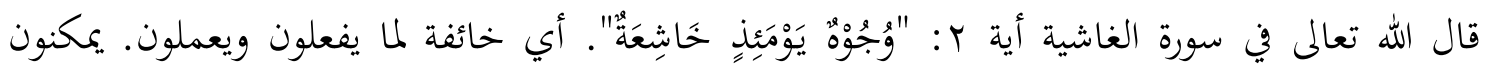
الناس أن يعملون السيئات والمعاصي والعقوق. كان الناس ينزعون وجوههم إلى الله خاشعة وخائفة وتوضعا. هم يرجون العفو من الله تعالى. ويتمنون إلى الله أن يعطيهم الرحمة.

قال الإمام العلامة تقي الدين ابن تيمية بأنّ هذا اليوم وجوه الناس في الدنيا خاشعة عاملة ناصبة تصلى يوم القيامة نارا حامية، ويعني بها عباد الكفار كالرهبان، وعباد اليهود، وربما تؤولت في أهل البدع كالخوارج. وأها يوم القيامة تخشع أي تذل تعمل وتنصب.

أفكر ليس يكون الكفار وحدهم الذين يخشون بيوم القيامة ولكن المسلمون الذين لا يؤمنون بالله ورسوله ويحبون السيئات هم يخشون بها بل للمسلمين يكونون يخشون بقلة الأعمال الحسنة. المهم جميع الناس يخشون بيوم القيامة لأنّ ذلك اليوم يظنون آخر الحياة في الدنيا.

قال الإمام أبو الفداء إسماعيل ابن كثير الدمشقي في تفسير ابن كثير بأن العشار هي الجمال الإناث المختار الحامل في عصر عشرة شهور. عندما يقع يوم القيامة، لا يبال الناس العشار وينسوها رغم أفم يحبون الجمال وهي أثمن المال عند العربي. كما قال الله تعالى في سورة التكوير أية ع: "وَإِذَا الْعِشَارُ عُطِلَتْ".

على الطبيعي، كان الناس يعملون الحسنات والسيئات عندما يعيشون في الدنيا. حينما كثرت أعمال الحسنات فجزاؤهم الجنة. وبالعكس، حينما كثرت أعمال السيئات فجزاؤهم جهنم. قبل أن يعرفوا حاصل أعمالهم، ينظرون الصحف التى يكتب ملكان هما رقيب وعتيد. حينئذ، يدعو الناس الله كثيرا ليطلبوا العفو

${ }^{11}$ Abdullah bin Muhammad bin Abdurrahman bin Ishaq Alu Syaikh, "Tafsir Ibnu Katsir: Jilid 8", (Bogor: Pustaka Imam asy-Syafi'I, 2004), hlm. 432.

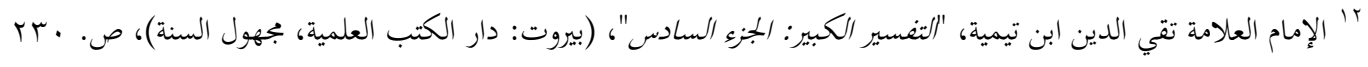

13 Al-Imam Abul Fida Ismail Ibnu Katsir ad-Dimasyqi, “Tafsir Ibnu Katsir: Juz 30”, (Bandung: Sinar Baru Algensindo, 2007), hlm. 99. 
Malia Fransisca

والرحمة من الله تعالى. ولكنهم متأخرون وباطلون ماكانوا يعملون. غلقت الصحف. بعد ذلك تفتح الصحف

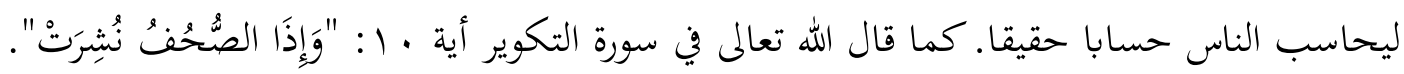

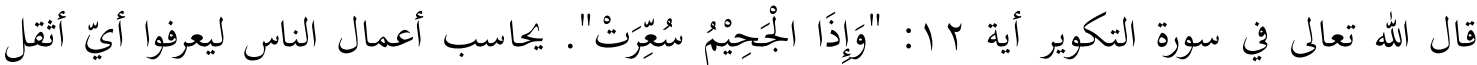
أعمالم. هل أعمال حسناقم أو سيئاقم. عندما أثقل أعمال سيئاتم يدخلون النار التى سعرت النار. حيئذ، تثاءبت النار واستعدت أن يقبض النار بشدة آلام. يسعر النار كيبرا عندما كثيرا من الناس يدخلون فيها. لأنّ

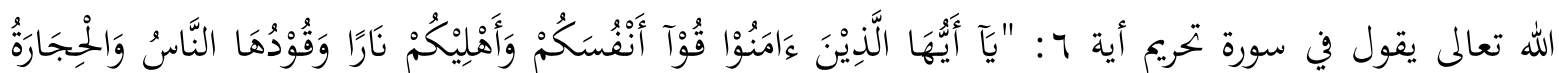

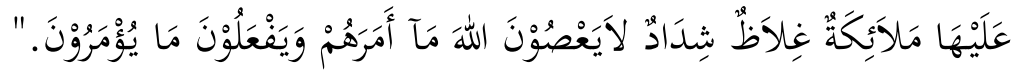

قال مجد الدين في سورة التكوير أية ا: "إذذا الشَّمْسُ كُوِرَتْ" يقول تكور كما العمامة ويرمى بها في

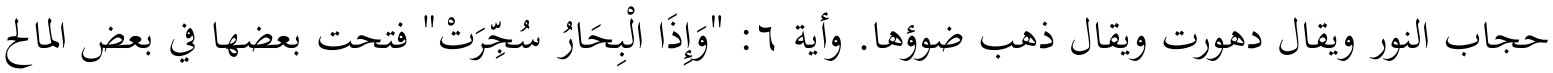

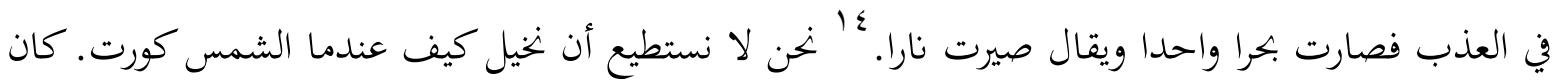
شكل الشمس مدور ثم تكور كيفما شكلها تبقى هو المدور. يمكن المقصود من هذه الأية هي يضيع نور الشمس. نحن نعرف بأن نور الشمس هو يضيء الأرض فكيف عندما الشمس كورت ثم لن تضيعها؟ كان الناس لم يستطع أن يعملوا الأنشطة لأن بعضهم يحتاجون إلى ضوء الشمس.

جاتمة

أيها الإخوان والأخوات... بعد أن نعرف كيف الحوادث عند القيامة، نحن نشعر أصغر المخلوقات في هذا العالم. لأنّ الحيونات الأكبر يموتون أيضا مثل الفيل والدينوصورات والزرافة لا سيما نحن أي الناس. عندما يتحرك الريح بشدة، كان الناس يطيرون بذلك الريح. عندما يزلزل الجبال، يجرى ويفر الناس ليجتنبوا لكي لايصيبهم. عندما يصب البحر في البر يهلك ما فيه وما يقي منها. عندما ينزل المطر أربعين يوما تحير الناس لأنّ يصير الفيضان. ما أصغر نحن من الناس حتى يمثل بالفراش عند يقع يوم القيامة.

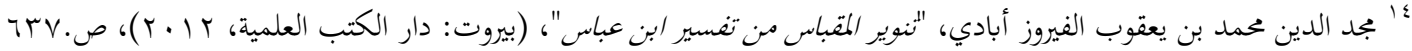


فلذلك... هيا بنا أن نذكر القيامة ونعمل الصالحات ونجتنب الطاغوت والسيئات ونأمر المعروف وننهى عن المنكر واكثروا الصدقة ولا يظلم الآخر وبر الوالدين ونعامل البيئة بخير ونخظها حسنة. لأنّ الأرض تملك بما كسبت أيدي الناس أنفسهم لطماعهم ولتفخر أموالهم.

لا تشغلوا على أمور الدنيا حتى تنسوا آخرتكم. الحياة الحقيقة هي في الآخرة ليس في الدنيا. ندعو إلى الله بحسن الخاتمة لكي لا نلتحق حوادث القيامة التى الداهشة شديدة. قيل سوءكم الذين يلتحقون يوم القيامة. فلذلك كثير من أوليآء الله يتوفون أولا أي هم من السابقين. اللهمّ إني أسألك حسن الخاتمة وأعوذ بك من سوء الخاتمة. آمين.

\section{المراجع}

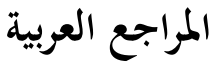

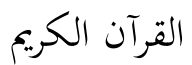

ابن تيمية، الإمام العلامة تقي الدين. "التغسير الكبير: الجزء السادس". بيروت: دار الكتب العلمية.

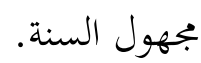

بن مسعود، الإمام أبي الحسين. "تنسير البغوى". بيروت: دار الكتب العلمية. بو9 19. الصابوني، محمد علي. "صغوة الثناسيز: المجلد الثاني". بيروت: دار القرآن الكريع. اله 1 ا. جابر الجزائري، أبي بكر. "أيسر التناسير لكلام العلي الكبير". المدينة المنورة: مكتبة العلوم والحكم. .$Y \cdot V$

محمد بن أحمد المحلى والعلامة جلال الدين عبد الرحمن بن أبي بكر السيوطي، العلامة جلال الدين. "تنسير الجلالين".بيروت: دار الكتب العلمية. مجهول السنة.

محمد بن يعقوب الفيروز أبادي، مجد الدين. "تنوير المقباس من تفسير ابن عباس". بيروت: دار الكتب

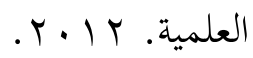




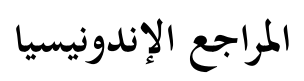

Ad-Dimasyqi, Al-Imam Abul Fida Ismail Ibnu Katsir. Tafsir Ibnu Katsir: Juz 30. Bandung: Sinar Baru Algensindo. 2007.

al-Maraghi, Ahmad Mushthafa. Terjemah Tafsir al-Maraghi. Tanpa Kota: 1365 H. Toha Putra.

Abdullah bin Muhammad bin Abdurrahman bin Ishaq Alu Syaikh. Tafsir Ibnu Katsir: Jilid 8. Bogor: Pustaka Imam asy-Syafi' I. 2004. 